\title{
How to Transversely Develop Ability Emotional Intelligence Ability through School Subjects? A Theoretical Proposal
}

\author{
José M. Mestre \\ Universidad de Cádiz, Department of Psychology, Puerto Real, Cádiz, Spain
}

\begin{abstract}
Since emotional intelligence (EI) was developed in 1990, the field of Education took advantage of the possibilities of EI. Indeed, EI-specific programs proliferated and developed as socio-emotional learning programs (SEL). However, there is an alternative to realize non-specifically and longer and viability way for improving the implicit abilities of EI (AEI). The article claims to work a theoretical proposal to develop the AEI in compulsory education through the subjects. This proposal is based on the Cattell-Horn-Carroll theory of cognitive abilities (CHC). CHC abilities are stimulated by most of the mandatory subjects of both Primary and Secondary Schools. The second stratum of CHC model is composed of similar cognitive abilities as 1997-Ability Emotional Intelligence Model (perception, using, understanding, and managing emotions), which is different from trait EI approaches - that consider EI has personality traits as well. It has pointed out that the capacities of the CHC-model second stratum are connected to the capabilities of AEI. Therefore, any educational activity that optimizes perception, understanding, attentional control or planning is affecting the development of AEI. Promoting AEI involves hot information processing. It is convenient to use transversely hot information processing - this means that this information has special meaning for the people. Connecting hot information to mandatory subjects teaching would develop the abilities of EI. Both Sciences and Natural Sciences pedagogic devices can improve emotional perception. However, Social Sciences and Humanities foster both emotional understanding and knowledge. Finally, the different contingencies that occur in school life scenarios are suitable for training of emotional regulation.
\end{abstract}

Keywords: ability emotional intelligence, emotional education, Cattell-Horn-Carroll theory of cognitive abilities, socio-emotional learning

\section{What is Ability Emotional Intelligence? An Update}

Let us try to solve the next emotional statement: Which emotional state may result in a constant worry? Think about it for a while and decide on one from the next list of emotions: disgust, anxiety, sadness, joy or anger. Based on the traditional

José M. Mestre, Department of Psychology, Faculty of Education Sciences, University of Cadiz, Polígono Río San Pedro, Puerto Real, Cádiz 11510, Spain. E-mail: josemi.mestre@uca.es 
emotional knowledge, the only possible answer is anxiety (Cisler, Olatunji, Feldner, \& Forsyth, 2010). Anxiety is a secondary emotional state that affects a person's perception of existential life, whose central cognitive process is to be concerned (Lazarus \& Lazarus, 1996). Another emotional intelligence question, perhaps even more challenging than the first, is this: How can people effectively regulate their anxiety state? The relationship between cognitive performance and anxiety arousal follows Yerkes-Dodson Law (1908) (see Figure 1), i.e., medium levels of anxiety involve better cognitive performance than both lower and higher levels of anxiety (Oatley \& Johnson-Laird, 2014). Hence, people who can regulate their anxiety states to medium levels are using their ability emotional intelligence (AEI) (Mestre, MacCann, Guil, \& Roberts, 2016). This type of emotional decision-making implies an intelligent act (Salovey, Hsee, \& Mayer, 1993) because people use the information set on their emotional processes to help them make more effective decisions, especially when making decisions using the controlled cognitive system instead of the automatic one (Kahneman, 2011).

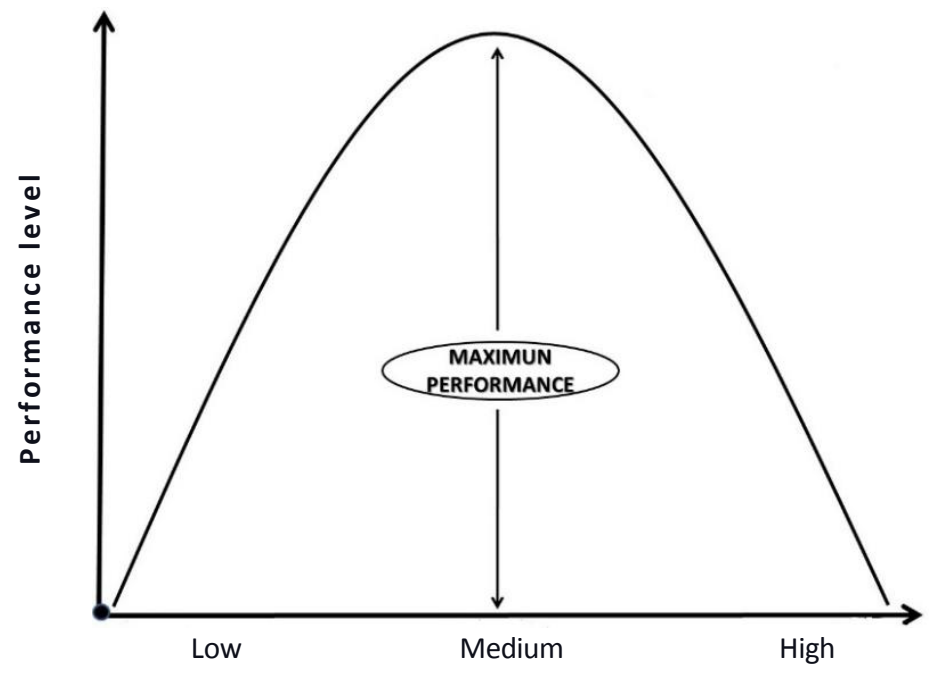

Figure 1. Yerkes-Dodson Law (1908).

Like any other intelligence, ability emotional intelligence (AEI) has to be addressed to solve problems related to social functioning (Guil et al., 2018), especially when the information we use come from emotions (Lopes et al., 2004).

In 1990, Salovey and Mayer proposed the existence of this intelligence based on research in different areas, such as cognition, emotion, intelligence or psychotherapy, suggesting that some people might be more intelligent with emotions than others (Salovey \& Mayer, 1990). Subsequently, they pointed out what cognitive abilities are in their AEI's theoretical framework, following a hierarchical model, from bottom to the top, described as perceiving, using, understanding, and managing emotions in oneself and others (Mayer \& Salovey, 1997). This 1997-AEI model has 
a hierarchical development as well, hence, the lowest level, perception, is going to develop earlier than the others (Mayer \& Salovey, 1997).

However, some authors have defended that the second ability, using emotions, should be integrated within the other three (see, for example, Mestre et al., 2016; Mikolajczak, 2009). Thus, ability emotional intelligence (AEI) would have three main abilities: perception and expression of emotions, understanding and knowledge of emotions, and emotional regulation (Hughes \& Evans, 2016).

\section{Seven Principles for the Last Update about Ability Emotional Intelligence}

With the $25^{\text {th }}$ anniversary of the ability emotional intelligence (AEI), Mayer, Caruso, and Salovey (2016) have established seven principles that AEI should follow: The first is that the AEI is a mental capacity. This is an obvious principle if we bear in mind that the term AEI carries the noun intelligence and the adjective emotional. Some EI approaches, such as trait emotional intelligence (TEI), argue that the term includes certain personality traits (see Petrides et al., 2016). However, the AEI approach tries to keep the EI as a new theoretical construct of intelligence, albeit in a broader sense than intelligence's psychometric tradition (Iliescu, Ilie, Ispas, \& Ion, 2013; MacCann, 2010; Mayer, Roberts, \& Barsade, 2008). If the intelligence is the capacity to carry out abstract reasoning, to understand meanings, to know how to distinguish between similarities and differences between two concepts, to generalize situations from facts, and to understand when to apply exceptions, then this system of mental capacities (Detterman, 1982) can also be applied to emotions to identify how people are capable of accurately perceiving and expressing emotions, how people use emotions to facilitate their thinking, how they understand emotional processes and their meanings and to regulate and manage their emotions for a better social and personal functioning (Mayer et al., 2016; Mestre et al., 2016).

The second principle is that AEI is better measured as a capacity than as a trait. Like any intelligence assessment instrument, AEI should be measured by cognitive tasks (Kong, 2014). MacCann and colleagues have pointed out that it is difficult to justify why AEI could be measured differently from any other type of intelligence, especially because AEI is structured in a similar way to the current definitions of intelligence based on the CHC mental-capacity model - Carroll, Horn and Cattell (MacCann, Joseph, Newman, \& Roberts, 2014; MacCann \& Roberts, 2008; Mestre et al., 2016). Furthermore, it seems that people are imprecise in estimating their own intelligence and EI capabilities (Brackett, Rivers, Shiffman, Lerner, \& Salovey, 2006), so how can researchers be sure of these AEI self-estimations based on selfreports? (Mestre \& Guil, 2006). Does it make sense to ask people how emotional intelligent are they? Probably just in case we are interested in knowing their own perception of their AEI, which may be also useful to know (Mestre et al., 2016).

The third principle is that solving problems intelligently does not necessarily correspond to intelligent behaviour. For example, a gifted student is likely to achieve a good academic performance, but this cannot be assured because it has been broadly 
reported that gifted students may have a below-average academic achievement for different reasons (Betts \& Neihart, 1988; Callahan \& Hertberg-Davis, 2013; Clinkenbeard, 2012; Guignard, Jacquet, \& Lubart, 2012; Whitmore, 1980). Furthermore, AEI should be no different from other intelligence (Duckworth, Quinn, \& Tsukayama, 2012). For example, some male adolescents with high EI are socially undervalued by their peers and teachers, yet they demonstrated a good capacity for academic achievement and a certain level of educational resilience (Lopes, Mestre, Guil, Kramenitzer, \& Salovey, 2012; Mestre, Guil, Lopes, Salovey, \& Gil-Olarte, 2006). Curiously, this male pattern of high AEI is maintained with male high-school students who prefer using their emotional abilities for academic achievement rather than for social functioning. Conversely, female high-school students prefer using their AEI for keeping good social functioning and academic achievements (Mestre et al., 2006). In other words, the theoretically foreseeable prediction of good social acceptance is not always fulfilled in people with high EI, at least with a high percentage of secondary-school males with good performance in cognitive task test such as the MSCEIT (Mayer - Salovey - Caruso Emotional Intelligence Test; Mayer, Salovey, Caruso, \& Sitarenios, 2003).

Besides, let us not forget that the term intelligent is an adjective, while intelligence is a noun. Linguistic connotations are important not to get lost in terminological vagueness. Emotionally intelligent behaviour is more related to the TEI approaches and personality construct than intelligence (Mayer et al., 2016), although significant correlations (low and very low) were found between intelligence and personality (Joseph \& Newman, 2010).

The following two principles relate to how EI should be measured. Fourth, the content of an AEI test to be applied should cover the area of the problem to be solved. As a general rule, the intelligence tests have many items and are longer in duration, approximately 45 minutes in adults. An AEI test needs to cover a broad sphere of capabilities (perceiving, expressing, understanding, and managing emotions) in both personal and social functioning (Matthews, Zeidner, \& Roberts, 2012; Mayer et al., 2008). Testing intelligence requires to measure the whole framework and not just a few parameters of it (Nafukho, 2010), and, in the future AEI research, it is, therefore, necessary to assess AEI using different tests (by every single branch - perceiving, using, understanding, and managing) rather than a single and broader AEI measure, due to the construct validity issues (Lim, Lee, Pinkham, Lam, \& Lee, 2019).

How to assess AEI at different ages is related to construct validity issues. Both social and cognitive development is affected by brain maturity (Izard et al., 2008; Vogel-Walcutt, Schatschneider, \& Bowers, 2011; Vrtička, Bondolfi, Sander, \& Vuilleumier, 2012), which means that AEI is going to increase with age (Fariselli, Ghini, \& Freedman, 2008). Hence, the level of difficulty for an AEI test should rise with age (Van den Broeck, Hofmans, Cooremans, \& Staels, 2014). Among other reasons, it is not an easy task to build an AEI test for children because their AEI is still incipient; and also a good level of verbal understanding (a crystallized intelligence) (Alegre, 2010) is necessary, although non-verbal abilities are important 
for the development of AEI as well (Albanese, De Stasio, Di Chiacchio, Fiorilli, \& Pons, 2010).

Besides, to be able to understand social emotions, it is necessary to foster a cognitive development improvement (Allen et al., 2015; Elfenbein, Barsade, \& Eisenkraft, 2008; Fiori \& Vasely-Maillerfer, 2018). For this reason, many of the EI test for children just include emotional perception and expression tasks (Mestre, Guil, Martinez-Cabañas, Larran, \& de la Torre, 2011). An example of the complexity of social emotions for children is the development of the theory of mind, which begins close to four years of age (Lecce, Bianco, Devine, Hughes, \& Banerjee, 2014). Therefore, for instance, to test understanding and emotion management of children, it would imply a higher emotional knowledge to understand what role has the envy in a social comparison situation. At earlier stages of people's life, testing AEI should be centred on perceiving and expressing emotions (Mayer \& Salovey, 1997).

The fifth principle, quite related to the previous one, is that these EIperformance tests represent a score of how people's AEI are, and their differences in the score, in turn, reflect their mental ability to solve emotional content problems. Therefore, if the test includes items that poorly reflect the content of the EI, then these tests do not correctly represent what we want to measure and we could make erroneous forecasts (Mayer et al., 2016). The elusiveness of testing AEI has been reported several times (i.e., Sharma, Deller, Biswal, \& Mandal, 2009).

The sixth principle is that AEI is a broad intelligence, what means that AEI is better framed in those perspectives that have a molar vision of intelligence rather than a molecular one - such as the factorial perspective of intelligence (Mayer, Salovey, Caruso, \& Sitarenios, 2001). Therefore, EI is theoretically better framed in the adaptive perspective of intelligence (Mestre, 2003). The adaptive perspective of intelligence is represented by authors such as Gardner, Sternberg or earlier by Vygotsky or Piaget (Plucker \& Esping, 2014). This perspective argues that intelligence moves between broad and narrow capabilities. Specifically, the most influential intelligence model today is the Cattell-Horn-Carroll (CHC) (Schneider \& McGrew, 2012), which is also known as the three-stratum intelligence model (Schneider \& Newman, 2015). The CHC model has been matched with the AEI abilities at its second stratum (MacCann et al., 2014; Mestre et al., 2016). According to Figure 2, it is possible to foster the second-stratum cognitive abilities CHC's model with the AEI. At the top of the model is $g$ factor and at the bottom are the primary mental abilities. 


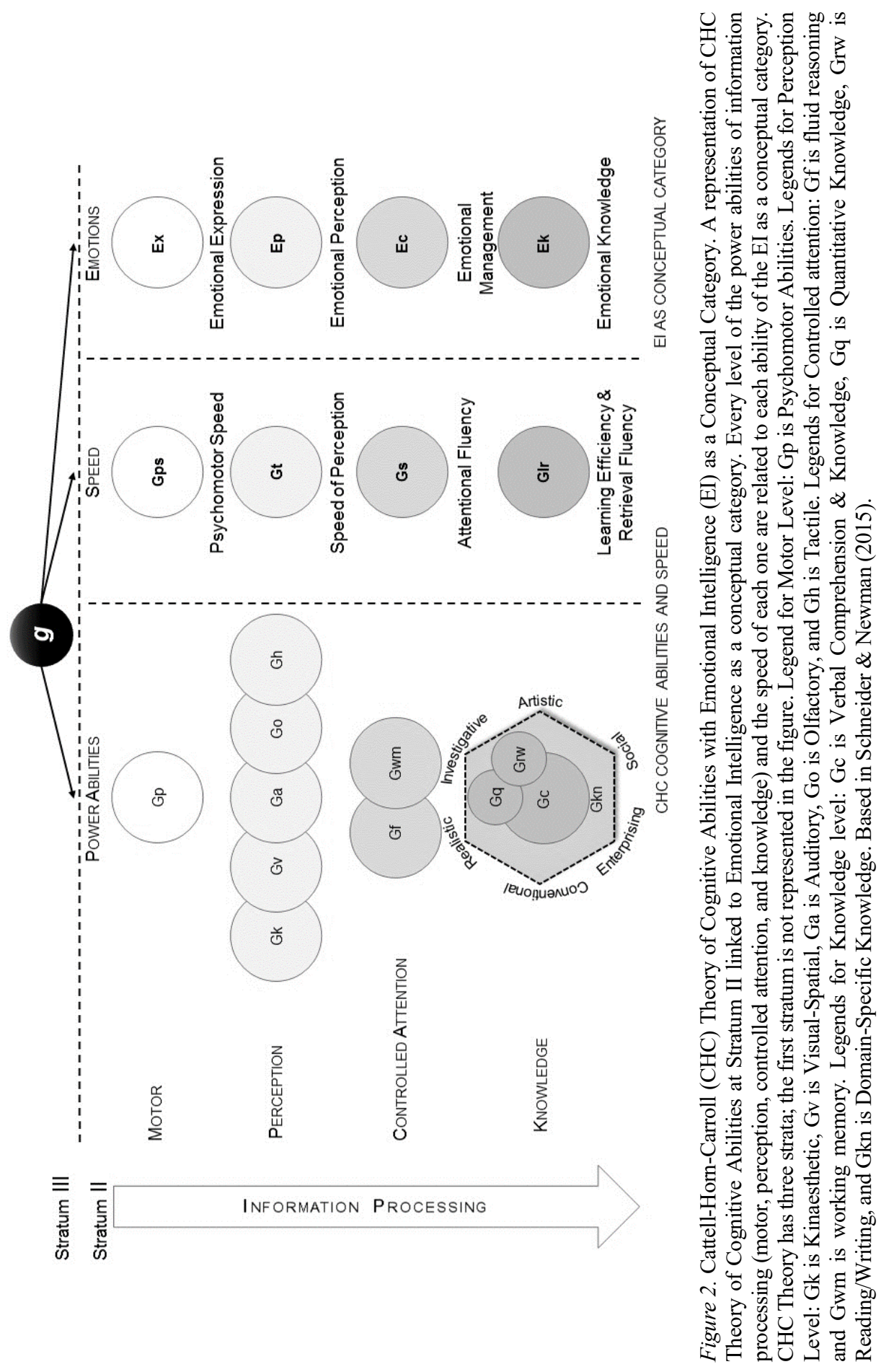


In the second stratum of the $\mathrm{CHC}$ model, there are broader cognitive abilities than in the first (see Flanagan \& Dixon, 2013; McGrew, 2009). In this level, it has been reported that AEI's branches are closely related to perception and motor expression (with perceiving and expressing emotions), attentional control (with emotional regulation), and knowledge (with understanding emotions) (MacCann et al., 2014; Mestre et al., 2016). These relationships are reflected in Figure 3. Although in a posterior reanalysis of the data, Legree et al. (2014) found the four components of AEI in the second stratum of the CHC model.

To summarize, it might be hypothesized that by developing the capacities of the CHC's second stratum, abilities set in the AEI framework will also be developed (Mestre et al., 2016). Therefore, if the contents of the subjects such as maths, natural sciences, humanities, and social sciences develop the CHC model's abilities, the next assumption would be that AEI might also be positively affected by this development. Recently, a positive relationship between AEI and academic achievement has been reported in a meta-analysis (MacCann et al., 2020), however, I strongly believe that this relationship between AEI and academic achievement is probably complementary, which means that higher academic achievement during school stages will also develop higher AEI scoring. Next, and the last principle would give a clue of how to transversely implement AEI over school subjects.

The seventh and the last principle of Mayer et al. (2016) is that EI is focused on the processing of information involved with information that has special meaning for individuals (in fact, they called it hot information processing). Mayer et al. (2016) divided processing information into hot and cool. Cold information is information related to facts or meanings of no personal value to people, like the calculation of a mathematical equation. However, hot information is any information that has meaning to an individual, as social acceptance, coherent identity, or emotional wellbeing (Mestre et al., 2016). Unlike other intelligences, AEI deals with hot information, which has an adaptive value and meaning for people (Mayer et al., 2016). Understanding this difference between hot and cold information is important to develop the AEI in people, hence, any mental activity that connects cognitive capacity with this type of information is, theoretically, an act of EI development (Gutiérrez-Cobo, Cabello, \& Fernández-Berrocal, 2016).

Emotions have an adaptive function (Izard et al., 2011), hence, AEI is using the hot information set for improving our social and personal functioning (Barchard, Brackett, \& Mestre, 2016; Mestre \& Barchard, 2017). Besides, Mayer et al. (2016) pointed out that the AEI use this hot information from emotions with precision and accurately.

With all arguments exposed above, how could research on ability emotional intelligence be carried out without implying a revolution in the curricular projects of schools? Several EI programs at school and their impact are documented (Nathanson, Rivers, Flynn, \& Brackett, 2016). However, it is also demonstrated that it is better to 


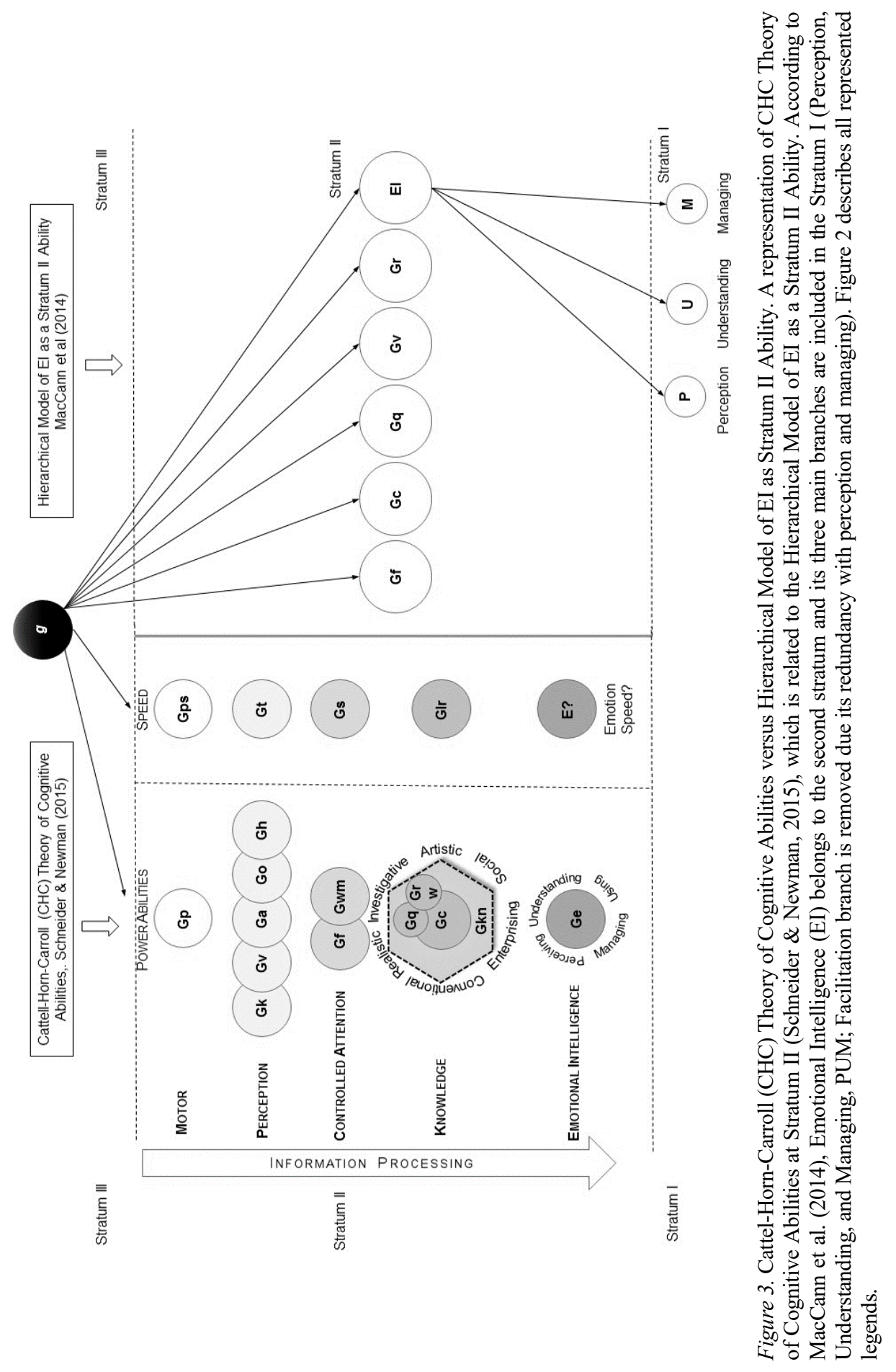


implement it transversely and through several school years than through a brief educational program (UNESCO, 2014).

\section{The Relationship between Ability Emotional Intelligence and both Social and Personal Functioning at School}

Durlak, Domitrovich, Weissberg, and Gullotta (2011) conducted a metaanalysis showing the results that integrate a systematic process of social-emotional development programmes (called social-emotional learning, SEL). According to authors, the implementation of these SEL programmes increases academic success, shows improvements in the relationship between pupils and teachers and reduces disruptive behaviour in the classroom (Durlak et al., 2011). SEL refers to the processes involved in the development of emotional knowledge and the regulation of emotions in oneself and others that improve interrelationships and socially desirable decision-making (Durlak et al., 2015).

Under SEL programs at school, their AEI implementations have improved wellbeing, quality relationships, academic performance, and school adaptation (Mestre et al., 2006; Nathanson et al., 2016). This relationship is a good social and educational investment (Belfield et al., 2015) but there is need for teaching long-term SEL skills in educational settings (Brackett \& Rivers, 2013; Nathanson et al., 2016). However, it is not easy to change traditional educational systems and to add SEL long-term programs. Although short-term SEL programs, such as RULER in the USA (Nathanson et al., 2016) or INTEMO for adolescents in Spain (Ruiz-Aranda et al., 2013), have been implemented, little is still known about the long-term effects of these SEL programs (MacCann et al., 2020).

Using hot information processes, it is feasible to teach AEI transversely through the school subjects. Any school-cognitive activity is likely going to improve any ability set in the EI framework (Mestre et al., 2016). Instead of short-term AEI programs, it is more desirable to implement longer ones. However, as far as we know, there are no experiences of implementing an AEI subject or a long-term AEI program at school because this option implies a strong will among policymakers - despite good outcomes after short SEL experiences. Nonetheless, there is an alternative nonspecific approach. Instead of a specific AEI program, it is feasible to include meaning and significance (hot information) in most of the subjects. Then, the AEIimplementing challenge is how to include this meaningful information in traditional subjects. According to Figures 2 and 3, the connection between EI abilities and CHC's cognitive abilities would provide generalisations of the education-emotion programs, and there are enough school scenarios for this promising relationship (Deneault \& Ricard, 2011; Kemeny et al., 2012; Lopes et al., 2012; MacCann et al., 2020; Nathanson et al., 2016; Petrides, Frederickson, \& Furnham, 2004).

For example, Ivcevic and Brackett (2015) pointed out that explicitly teaching of AEI also enhances students' ability to solve complex and real problems in daily life (even at school stages). Wouldn't it also be the other way around? If students pay 
attention (second stratum, attentional control) during the resolution of a math problem, and based on their math knowledge (knowledge, see Figure 2) they may successfully solve the math problem. Hence, students' increasing CHC's abilities set in the ability emotional intelligence, too. Most of the school subjects require the development of cognitive abilities and skills and vice-versa. Next section tries to explain how to include this hot-emotional information in some key school subjects.

\section{Developing Ability Emotional Intelligence Transversely through School Subjects}

As we stated before, some authors consider the second AEI's branch, using emotions, to be set within the other branches. Hence, we can focus on the rest of the EI abilities. On the one hand, natural sciences and the science can help the development of both perceiving and understanding emotions. Solving science tasks may improve the attentional control, and so emotional regulation may improve as well (see Figures 2 and 3). On the other hand, social sciences and humanities may be very useful in fostering emotional understanding in social-functioning situations. Besides, the different contingencies arising from the social interaction between students and teachers, and the students among themselves, are valid opportunities for growth of students' ability to regulate emotions.

\section{How Science and Natural Sciences Can Optimize the Ability to Perceive Emotions Accurately? Some Suggestions}

Sciences and natural sciences are linked to the development of cognitive abilities. To understand a science problem, we need to perceive and understand the situation accurately, to make the best decision for solving the problem, to monitor it, and to check and implement a strategic plan. Hence, to develop ability emotional intelligence, students also need to improve the required abilities in these subjects.

All cognitive and emotional processes begin and end with the perception. Regarding EI, perceiving emotions is the capacity by which AEI begins to be activated (Mayer et al., 2016). Besides, the key to perceiving emotions relies on the term accurately (Mayer \& Salovey, 1997). However, to say precise can be necessary, yet not enough. Because perception is a double process, mostly simultaneous, of the so-called top-down and bottom-up processes (top-down vs. bottom-up, Kosslyn \& Miller, 2013).

On the one hand, according to Galotti (2008), bottom-up processes occur when people comprehend in terms of what we perceive from the data, just like they are strictly to what sensory organs perceive from social-interaction situations or environment. Hence, bottom-up processes improve the accuracy of perceiving emotions, but they also imply a greater mental effort and not being mediated by automatic filters such as beliefs, stereotypes or prejudices (Mestre, Gutierrez, Guerrero, \& Guil, 2017). Besides, this bottom-up cognitive process is one of the 
goals of mindfulness-based intervention, which also searches to perceive emotional experiences without valuing and to clean the cognitive filter of the turbidity of preconceived ideas (Turanzas, Cordón, Choca, \& Mestre, 2020). On the other hand, top-down cognitive processes are related to how people interpreted their gathered information from sensory organs and most of these top-down processes are an automatic process, which leads people to wrong decision-making (Kosslyn \& Miller, 2013). This top-down process encompasses mental capacities involved in directing both observation and external stimuli towards prior ideas acquired from an already acquired exploration (Goldstein, 2008). Therefore, most of the emotional perceptions might not be accurate and will require emotional perception training (García-Gómez, Guerra, López-Ramos, \& Mestre, 2019). Accurately perceiving emotions will require mental effort, paying attention to the stimulus carefully - labelling accurately the emotional expressions of others (Elfenbein et al., 2008). Consequently, it is more effective to identify emotions by what our senses report to us than by what our expectations report to us, which would be a top-down process (Mestre et al., 2017).

According to Kahneman (2011), when people make decisions, they follow two reasoning system (with or without the involvement of the emotions). System 1 operates quickly and automatically, with little mental effort and without a sense of attentional control. Conversely, System 2 focuses attention on challenging mental activities such as a complex math calculation or as a social-emotional conflict between two friends. This System 2 implies the use of attention so that this cognitive activity is not disturbed. System 2 activities are likely similar to: being attentive to the definition of a problem, paying attention to school-subjects explanations, being able to carefully listen to an answer after an inquiry, looking for the correct answer in a school multiple-choice test, observing an adequate teacher's behaviour after mediating during a peer's conflict in the classroom and so on. All these actions require attention, concentration, cognitive planning, monitoring, understanding and management of available information. In the same way that EI needs attentional control for the development of an action that allows a successful solution, for example in an emotional conflict (Mestre et al., 2016). Without the active role of attention, these activities are performed poorly or not at all, and it is linked to the mental effort and learning processes (Kahneman, 2011).

Therefore, the difference between an accurately and not-accurately (miss/over interpretation) of emotions relies in using the Kahneman's system 2, the mental effort, and the controlled learning processing (Breslin, Zack, \& McMain, 2002; Dodonova \& Dodonov, 2012; Pell, Jaywant, Monetta, \& Kotz, 2011; Swart, Kortekaas, \& Aleman, 2009; Wells, 2002). Any controlled learning processing is occurring during school stages (Griffiths \& Tenenbaum, 2006). For instance, Medina, Pérez-Alarcón, Reyes, Ceballos-Zúñiga, and Mestre (2012) related both AEI (measured with the MSCEIT) and social-sensitivity scores (measured with the TESIS, Barraca, Fernández-González, \& Sueiro, 2009). Findings showed that the people with the lowest AEI scores were also those who scored significantly highest on the TESIS's over-interpretation subscale. However, high social sensitivity that 
implies precision in emotional judgments, was significant and positively related to AEI. Therefore, AEI avoids using biases when people are using their emotional perception to judge social-emotional interactions (Medina et al., 2012).

The rule to be followed may be related to the learning opportunities at school. Any school activity, which improves both cognitive and emotional information processing, will improve emotional perception ability. For example, both social and emotional conflicts at school are common among school peers and between students and teachers (Waters \& Thompson, 2014). These emotional experiences, positive or negative, will lead students to observe how their teachers solve emotional conflicts at classroom. For example, Mayer and Salovey (1997) described an example of school peer conflict - after the reasons were explained between involved students and teacher, all classroom peers had to write a brief redaction of why that situation happened so they could talk about it later. Writing requires interesting cognitive abilities related to AEI. Later, students had to read their redactions in front of the rest of peers, they had to pay attention in their thoughts about the conflict, to give explanations, to understand and identify causes and effects. This implies spending school time in solving social and emotional conflicts in the classroom; however, this also provides another type of learning and improves social adaptation at school (Mestre et al., 2006). Besides, vicarious learning through teachers' emotional managing is another learning opportunity. When teachers use their emotional experience for solving school conflicts, students learn emotional intelligent behaviours and resilience from them (Cassidy, 2015; Windingstad, McCallum, Mee Bell, \& Dunn, 2011).

For science to improve emotional-cognition abilities as well, it is necessary to introduce meaning and hot information in these subjects. For example, imagine this simple math problem: to John, a 9-year-old boy, his mother gave 20 euros so he can buy candies for his classmates because that day was his birthday and he wanted to share his happiness with them. Regrettably, just before entering in the candy store, John noticed that he had lost several of the most valuable coins along the way, so John had 7 euros and 56 cents left. The question is obvious; how much money did John lose? A primary-school student likely knows to subtract the 7.56 euros from 20 to know that 12.44 was the solution. But what if we add one more question? If you were John, how would you feel after losing a good part of the money that your mother gave to you to buy candies for your classmates? Let us imagine that children have to pick up an answer from next options: sad, angry, surprised or worried. When someone lost something valuable to them, sadness is the expected emotion (Zimmermann \& Iwanski, 2014). However, students, who answered angry might have a lack frustration tolerance (Guerra et al., 2019); those that picked up surprised it could be due to their lack of social sensitivity (Toivonen et al., 2012), and worried is a signal of social anxiety (Anastopoulos et al., 2011). Therefore, when a science teacher introduces hot information and meaning to their students' school activities, there is an opportunity to increase emotional knowledge, AEI or theory of mind 
among students. Besides, when AEI is being developed, their academic achievements are also improving (MacCann et al., 2020).

Perceiving, understanding, and managing emotions are not quite different from perceiving, understanding, and managing science challenges. When students are performing and implementing science strategies they are also improving their cognitive abilities that are involved in the emotional intelligent behaviour.

\section{Social Science and Humanity Subjects Can Optimize Emotional Understanding and Knowledge}

Nowadays, humanities and social sciences do not have the same status as science and natural sciences. However, humanities have an interesting role in the development of knowledge and social-functioning understanding.

Understanding emotions is a capacity that is closely linked to crystallized intelligence $(G c)$ (Husin, Santos, Ramos, \& Nordin, 2013), which is based on experience and accumulated knowledge (Mestre et al., 2016). The accumulation of knowledge through lived experiences, learning, readings, and culture activities improve the abilities related to $G c$. The emotional knowledge is also part of this $G c$ and has been considered as "the core of intelligent regulation" (Wranik, Barrett, \& Salovey, 2007, p. 395). Understanding how emotions combine, progress and change over time and situations (Mayer \& Salovey, 1997) requires a lot of both learning and instruction, to such an extent that the evolutionary and adequate development of EI requires an appropriate cognitive, social, moral, emotional and linguistic development (Carpendale \& Lewis, 2004; Hawn, Overstreet, Stewart, \& Amstadter, 2015; Petrides et al., 2016). Besides, understanding social emotions (guilt, shame, jealousy or anxiety, for example) requires more time than basic emotions (joy, sadness or anger, for example) (Izard et al., 2011).

Subjects linked to the social sciences and humanities can contribute the most to the emotional knowledge improvement, and, hence, emotional understanding. In fact, the third AEI branch, emotional understanding, has achieved the best positive and significant relationship with academic performance in this type of subjects (Durlack et al., 2015) because students have feedback with social-learning experiences.

For example, literature is a subject that may provide meaning significance to emotions, especially, social emotions. Shakespeare's Othello is an opportunity to understand the differences and connections between jealousy and envy. Othello's plot is complex, but understanding the role of emotions in the characters of Iago and Othello helps to understand the differences between envy and jealousy (Crawford, 2009).

Understanding the character motivations of Shakespeare's book requires to know why Othello feels jealousy and Iago feels envy. What are the mechanisms that lead them to feel that way? Instead of describing "Othello", it would be 
recommendable to use hot information to understand its plot and why jealousy and envy were induced by the contingencies of its characters. The Moor Othello is a general in the service of Venice; he has won the love of Desdemona, daughter of Senator Brabantius - the Dux of Venice. In the beginning, Iago wants a military promotion, however, he suspects that the post was given to Cassio because of Desdemona's friendship with him and because he was a go-between in the courtship of Othello and Desdemona. For this reason, Iago declares his hatred for the pair. Iago envies Cassius and succeeds in discrediting him by getting him drunk and disturbing the public peace. Cassio was deprived of his degree, yet the envious Iago induces Cassius to beg Desdemona to intercede on his behalf; simultaneously, Iago makes Othello suspect that his wife is cheating on him with Cassius. The Machiavellian action of Iago takes effect when Desdemona intercedes with Othello on behalf of Cassius. This provokes in Othello the confirmation of the suspicions induced by Iago and creates in him feelings of jealousy. The envious Iago manages to have a piece of garment that Othello gave to Desdemona be found in Cassius' possession. Othello, blinded by jealousy, strangles Desdemona in her bed. Finally, Iago's plot is discovered, and Othello commits stoic suicide.

Jealousy is emotion in which two people are involved, however, jealousy needs three, in which the jealous person feels threatened by the belief that their partner feels something for a third person (Salovey, 1991). Understanding the transition between emotions and the causes and relationships of a literary work undoubtedly helps to understand complex-plot emotions. The subjective state of an envious person is to want what the other person has, and in a hostile attitude to come to wish that the other person loses what the envious person longs for (Lazarus \& Lazarus, 1996).

The plot of Shakespeare's Othello points out that there are real and academic possibilities where students can be, in maieutic manner, interrogated and stimulated to find answers and increase the opportunities of students to improve their knowledge about emotions, especially the social emotions that have a higher cognitive demand than the basic ones (Mestre et al., 2017). Specifically, if we include hot information as emotional plots in this type of subjects, we are also promoting the understanding of emotions. History or literature, and even religion or ethics, are susceptible to being transversally analysed for emotions.

Literature, history, and language have a key role in the development of crystallized intelligence; hence, knowledge and relevant experiences are crucial for development of emotional knowledge as well.

\section{School Interactions are Relevant Learning Experiences for Promoting Emotional Regulation}

Social functioning is a relevant outcome highly linked with mental health (Mestre et al., 2016), and the development of a good emotional regulation provides an important mediating role between positive mental health and their mechanisms of change (for example, teaching at school). 
Emotional regulation (ER) focuses on the process of how people use certain abilities (especially, appraisal and attentional control) to influence what emotions they have, when they have them, and how they have to be expressed (Gross \& Thompson, 2007). Gross and Feldman-Barrett (2011) described ER as a transaction where there is a given situation that involves a person's attention towards a relevant goal, which activates an interpretation and a response (cognitive, behavioural, and physiological). Peña-Sarrionandia, Mikolajczak, and Gross (2015) suggested integrating, simultaneously, regulation of emotions and EI to understand how emotions are better or worse managed from individual differences on EI scores. People with a high EI use strategies such as positive reappraisal and direct modification of situations, however, those with a low EI score tend to use more avoidance and ruminative thinking (Peña-Sarriondia et al., 2015). To summarize, people with good EI seem to use a mechanism to translate their emotional knowledge into effective ER strategies (Mestre et al., 2016). This supports the view of the EI hierarchical framework of Mayer and Salovey's (1997), in which they postulated that an adequate development of an accurate perception of emotions is needed to later begin to understand them, and once a good knowledge has been developed, people can effectively manage their emotions.

School life is a socialization process (UNESCO, 2014), which involves and provides opportunities to develop the ability to regulate emotions. The desire to please others, to comply with the rules, to generate good academic performance, to avoid or diminish disruptive behaviour, to know how to mediate conflicts that arise, to negotiate with teachers or classmates, and to improve the quality of relationships within the community are situations that imply adequate management of emotions (Nathanson et al., 2016; Opateye, 2014; Sánchez-Álvarez, Extremera, \& FernándezBerrocal, 2015; Zeidner, 2017). Facilitating, advising and monitoring students to be the protagonists of these changes, situations or conflicts are opportunities for the development of the key capabilities for the complete development of EI, the regulation of emotions (Lopes et al., 2012; Parker, Summerfeldt, Hogan, \& Majeski, 2004).

Emotional regulation requires a major development of cognitive abilities set in the second stratum CHC model, especially development of attentional control (Mestre et al., 2016).

\section{Conclusion}

This proposal does not invalidate any specific EI intervention at school. Any activity to improve EI, even if it is short term, should be welcomed. However, in the long term, the effects of a short-and-specific EI intervention are often diluted over time. An alternative is that it is possible to promote EI in a transversal way by introducing hot information in many school subjects. Moreover, the cognitive abilities that most academic subjects foster are also implicit in EI. Unspecific training 
in EI is more realistic and certainly more effective in the long term. Ability emotional intelligence (AEI) shares at the CHC model's second stratum the same abilities: perception, attentional control and knowledge. Therefore, any school-based cognitive activity that is linked to the development of such second-stratum abilities of CHC model also promotes, although not directly, the development of EI, i.e., school adaptation and academic performance. An accurate emotional perception requires development of bottom-up perception processes that involve monitoring, changing and regulating stereotypes, prejudices or irrational beliefs that affect the emotional processes (Mestre \& Guil, 2012). Science and natural science subjects are appropriate for the development of emotional perception. A number of studies provides a proof of the importance of this capacity of perceiving emotions accurately, that combine mindfulness (which is negatively related to negative emotions) and EI, which is related to the promotion of affective states (Mestre et al., 2019). Mindfulness-based interventions provide tools for improving bottom-up processes (Flook et al., 2010) and EI interventions develop good emotional states and social functioning (Lopes et al., 2012; Lopes, Salovey, Coté, \& Beers, 2005; Mestre et al., 2006). It has been suggested, with promising outcomes, that mindfulness activities should be included in academic subjects (Zenner, Herrnleben-Kurz, \& Walach, 2014).

Regarding emotional understanding and knowledge, social sciences and humanities can be enhanced with the inclusion of hot information processes (such as social and existential emotions). Unfolding the plot and meaning of different themes of History or Literature would require improving reasoning, the ability to connect causes and effects and to understand the role of emotions (Mayer et al., 2016). Including hot information in these subjects also gives a meaning understanding as we described above with Othello.

Finally, emotional regulation implies a greater number of effort and cognitive development - including linguistic, social, emotional and moral. School's daily life is full of opportunities and interactions where students might be advised and guided by the teachers. Emotional regulation is the key capacity for solid personal and social functioning (Mestre et al., 2016).

This perspective of adding hot information to the teacher's task seems more viable and realistic, and we also implement a greater temporality of these influences in the development of students' EI. We hope, with this article, to stimulate teachers to this feasible challenge. 


\section{References}

Albanese, O., De Stasio, S., Di Chiacchio, C., Fiorilli, C., \& Pons, F. (2010). Emotion comprehension: The impact of nonverbal intelligence. The Journal of Genetic Psychology, 171(2), 101-115. https://doi.org/10.1080/00221320903548084

Alegre, A. (2010). Parenting styles and children's emotional intelligence: What do we know? The Family Journal, 19(1), 56-62. https://doi.org/10.1177/1066480710387486

Allen, V., Rahman, N., Weissman, A., MacCann, C., Lewis, C., \& Roberts, R. D. (2015). The Situational Test of Emotional Management - Brief (STEM-B): Development and validation using item response theory and latent class analysis. Personality and Individual Differences, 81, 195-200. https://doi.org/10.1016/j.paid.2015.01.053

Anastopoulos, A. D., Smith, T. F., Garrett, M. E., Morrissey-Kane, E., Schatz, N. K., Sommer, J. L., ... Ashley-Koch, A. (2011). Self-regulation of emotion, functional impairment, and comorbidity among children with AD/HD. Journal of Attention Disorders, 15(7), 583-592. https://doi.org/10.1177/1087054710370567

Barchard, K. A., Brackett, M. A., \& Mestre, J. M. (2016). Taking stock and moving forward: 25 years of emotional intelligence research. Emotion Review, 8(4), 289-289. https://doi.org/10.1177/1754073916650562

Betts, G. T., \& Neihart, M. (1988). Profiles of the gifted and talented. Gifted Child Quarterly, 32(2), 248-253. https://doi.org/10.16177/001698628803200202

Barraca, J., Fernández-González, A., \& Sueiro, M. (2009). Test de Sensibilidad a las Interacciones Sociales (TESIS): Una prueba objetiva para la medición de la inteligencia emocional [Social Interaction Sensitivity Test (TESIS): An objective test for the measurement of emotional intelligence]. Bizkaia: AlborCohs.

Belfield, C., Bowden, B., Klapp, A., Levin, H., Shand, R., \& Zander, S. (2015). The economic value of social and emotional learning. New York, NY: Columbia University, Center for Cost Benefit Studies in Education.

Brackett, M. A., \& Rivers, S. E. (2013). Transforming students' lives with social and emotional learning. In R. Pekrun \& L. Linnenbrink-García (Eds.), International handbook of emotions in education (pp. 368-388). New York: Taylor and Francis.

Brackett, M. A., Rivers, S. E., Shiffman, S., Lerner, N., \& Salovey, P. (2006). Relating emotional abilities to social functioning: A comparison of self-report and performance measures of emotional intelligence. Journal of Personality and Social Psychology, 91(4), 780-795. https://doi.org/10.1037/0022-3514.91.4.780

Breslin, F., Zack, M., \& McMain, S. (2002). An information-processing analysis of mindfulness: Implications for relapse prevention in the treatment of substance abuse. Clinical Psychology: Science and Practice, 9(3), 275-299. https://doi.org/10.1093/ clipsy.9.3.275

Callahan, C., \& Hertberg-Davis, H. (2013). Fundamentals of gifted education: Considering multiple perspectives. New York: Routledge. 
Carpendale, J. I. M., \& Lewis, C. (2004). Constructing an understanding of mind: The development of children's social understanding within social interaction. Behavioral and Brain Sciences, 27(01), 79-151. https://doi.org/10.1017/S0140525X04000032

Cassidy, S. (2015). Resilience building in students: The role of academic self-efficacy. Frontiers in Psychology, 6, 1781. https://doi.org/10.3389/fpsyg.2015.01781

Cisler, J., Olatunji, B., Feldner, M., \& Forsyth, J. (2010). Emotion regulation and the anxiety disorders: An integrative review. Journal of Psychopathology and Behavioral Assessment, 32(1), 68-82. https://doi.org/10.1007/s10862-009-9161-1

Clinkenbeard, P. (2012). Motivation and gifted students: Implications of theory and research. Psychology in the Schools, 49(7), 622-630. https://doi.org/10.1002/pits.21628

Crawford, A. W. (2009). Hamlet, an ideal prince, and other essays in Shakesperean interpretation: Hamlet; Merchant of Venice; Othello; King Lear. Shakespeare Online, 20. Retrieved from http://www.shakespeare-online.com/plays/othello/othellobradley2. html

Deneault, J., \& Ricard, M. (2011). Are emotion and mind understanding differently linked to young children's social adjustment? Relationships between behavioral consequences of emotions, false belief, and SCBE. The Journal of Genetic Psychology, 174(1), 88-116. https://doi.org/10.1080/00221325.2011.642028

Detterman, D. K. (1982). Does 'g' exist? Intelligence, 6(2), 99-108. https://doi.org/10.1016/ 0160- 2896(82)90008-3

Dodonova, Y. A, \& Dodonov, Y. S. (2012). Speed of emotional information processing and emotional intelligence. International Journal of Psychology: Journal International de Psychologie, 47(6), 429-437. https://doi.org/10.1080/00207594.2012.656131

Duckworth, A. L., Quinn, P. D., \& Tsukayama, E. (2012). What no child left behind leaves behind: The roles of IQ and self-control in predicting standardized achievement test scores and report card grades. Journal of Educational Psychology, 104(2), 439-451. https://doi.org/10.1037/a0026280

Durlak, J. A., Domitrovich, C. E., Weissberg, R. P., \& Gullotta, T. P. (Eds.). (2015). The handbook of social and emotional learning. New York, NY: The Guilford Press.

Durlak, J. A., Weissberg, R. P., Dymnicki, A. B., Taylor, R. D., \& Schellinger, K. B. (2011). The impact of enhancing students' social and emotional learning: A meta-analysis of school-based universal interventions. Child Development, 82, 405-432. http://doi.org/ 10.1111/j.1467-8624.2010.01564.x

Elfenbein, H. A., Barsade, S. G., \& Eisenkraft, N. (2008). Do we know emotional intelligence when we see it? The social perception of emotional abilities. SSRN Electronic Journal. https://doi.org/10.2139/ssrn.1314925

Fariselli, L., Ghini, M., \& Freedman, J. (2008). Age and emotional intelligence. Six Seconds: The Emotional Intelligence Network, 1-10.

Fiori, M., \& Vasely-Maillerfer, A. (2018). Emotional intelligence as an ability: Theory, challenges and new directions. In K. V. Keefer, J. D. A. Parker, \& D. H. Saklofske (Eds.), Handbook of emotional intelligence in education (pp. 23-47). Cham, Switzerland: Springer. 
Flanagan, D. P., \& Dixon, S. G. (2013). The Cattell-Horn-Carroll theory of cognitive abilities. In C. R. Reynolds, K. J. Vannest, \& E. Fletcher-Janzen (Eds.), Encyclopedia of special education (pp. 368-382). Hoboken, NJ: John Wiley and Sons.

Flook, L., Smalley, S. L., Kitil, M. J., Galla, B. M., Kaiser-Greenland, S., Locke, J., .. Kasari, C. (2010). Effects of mindful awareness practices on executive functions in elementary school children. Journal of Applied School Psychology, 26(1), 70-95. https://doi.org/10. 1080/15377900903379125

Galotti, K. M. (2008). Cognitive psychology: In and out of the laboratory (4 $\left.{ }^{\text {th }} \mathrm{Ed}\right)$. Belmont, CA: Thomson Wadsworth.

García-Gómez, M., Guerra, J., López-Ramos, V. M., \& Mestre, J. M. (2019). Cognitive fusion mediates the relationship between dispositional mindfulness and negative affects: A study in a sample of Spanish children and adolescent school students. International Journal of Environmental Research and Public Health, 16(23), 4687. https://doi.org/ 10.3390/ijerph16234687

Goldstein, E. B. (2008). Cognitive psychology: Connecting mind, research, and everyday experience ( $\left.2^{\text {nd }} \mathrm{Ed}\right)$. Belmont, CA: Thomson Wadsworth.

Griffiths, T. L., \& Tenenbaum, J. B. (2006). Optimal predictions in everyday cognition. Psychological Science, 17(9), 767-773. https://doi.org/10.1111/j.1467-9280.2006. 01780.x

Gross, J. J., \& Feldman-Barrett, L. (2011). Emotion generation and emotion regulation: One or two depends on your point of view. Emotion Review, 3(1), 8-16. https://doi.org/10.1177/1754073910380974

Gross, J. J., \& Thompson, R. A. (2007). Emotion regulation: Conceptual foundations. Emotion, 3(7), 3-24. https://doi.org/10.1080/00140130600971135

Guerra, J., García-Gómez, M., Turanzas, J., Cordón, J. R., Suárez-Jurado, C., \& Mestre, J. M. (2019). A brief Spanish version of the Child and Adolescent Mindfulness Measure (CAMM). A dispositional mindfulness measure. International Journal of Environmental Research and Public Health, 16(8), 1355. https://doi.org/10.3390/ ijerph16081355

Guignard, J. H., Jacquet, A. Y., \& Lubart, T. I. (2012). Perfectionism and anxiety: A paradox in intellectual giftedness? PLOS ONE, 7(7), e41043. https://doi.org/10.1371/journal. pone. 0041043

Guil, R., González-Fernandez, S., Mestre, J. M., Zayas, A., Guerrero, C., \& Gil-Olarte, P. (2018). New forms of social interaction: Virtual communication and health. Duazary, 15(3), 263-272. https://doi.org/10.21676/2389783X.2417

Gutiérrez-Cobo, M. J., Cabello, R., \& Fernández-Berrocal, P. (2016). The relationship between emotional intelligence and cool and hot cognitive processes: A systematic review. Frontiers in Behavioral Neuroscience, 10, 1-13. https://doi.org/10.3389/ fnbeh.2016.00101

Hawn, S. E., Overstreet, C., Stewart, K. E., \& Amstadter, A. B. (2015). Recent advances in the genetics of emotion regulation: A review. Current Opinion in Psychology, 3, 108116. https://doi.org/10.1016/j.copsyc.2014.12.014 
Hughes, D. J., \& Evans, T. R. (2016). Comment: Trait EI moderates the relationship between ability EI and emotion regulation. Emotion Review, 8, 1-2. https://doi.org/10.1177/ 1754073916650502

Husin, W. N. I. W., Santos, A., Ramos, H. M., \& Nordin, M. S. (2013). The place of emotional intelligence in the 'intelligence' taxonomy: Crystallized intelligence or fluid intelligence factor? Procedia - Social and Behavioral Sciences, 97, 214-223. https://doi.org/10.1016/ j.sbspro.2013.10.225

Iliescu, D., Ilie, A., Ispas, D., \& Ion, A. (2013). Examining the psychometric properties of the Mayer-Salovey-Caruso Emotional Intelligence Test. European Journal of Psychological Assessment, 29(2), 121-128. https://doi.org/10.1027/1015-5759/a000132

Ivcevic, Z., \& Brackett, M. A. (2015). Predicting creativity: Interactive effects of openness to experience and emotion regulation ability. Psychology of Aesthetics, Creativity, and the Arts, 9(4), 480-487. http://doi.org/10.1037/a0039826

Izard, C. E., King, K. A., Trentacosta, C. J., Morgan, J. K., Laurenceau, J. P., KrauthamerEwing, E. S., \& Finlon, K. J. (2008). Accelerating the development of emotion competence in Head Start children: Effects on adaptive and maladaptive behavior. Development and Psychopathology, 20(1), 369-397. https://doi.org/10.1017/ S0954579408000175

Izard, C. E., Woodburn, E. M., Finlon, K. J., Krauthamer-Ewing, E. S., Grossman, S. R., \& Seidenfeld, A. (2011). Emotion knowledge, emotion utilization, and emotion regulation. Emotion Review, 3(1), 44-52. https://doi.org/10.1177/1754073910380972

Joseph, D. L., \& Newman, D. A. (2010). Discriminant validity of self-reported emotional intelligence: A multitrait-multisource study. Educational and Psychological Measurement, 70(4), 672-694. http://doi.org/10.1177/0013164409355700

Kahneman, D. (2011). Thinking, fast and slow. New York: Farrar, Strauss, Giroux.

Kemeny, M. E., Foltz, C., Cavanagh, J. F., Cullen, M., Giese-Davis, J., Jennings, P., ... Ekman, P. (2012). Contemplative/emotion training reduces negative emotional behavior and promotes prosocial responses. Emotion, 12(2), 338-350. https://doi.org/10.1037/ a0026118

Kong, D. T. (2014). Mayer-Salovey-Caruso Emotional Intelligence Test (MSCEIT/MEIS) and overall, verbal, and nonverbal intelligence: Meta-analytic evidence and critical contingencies. Personality and Individual Differences, 66, 171-175. https://doi.org/10. 1016/j.paid.2014.03.028

Kosslyn, S. M., \& Miller, G. W. (2013). Top brain, bottom brain. New York: Simon \& Schuster.

Lazarus, R. S., \& Lazarus, B. N. (1996). Passion and reason. New York: Oxford University Press.

Lecce, S., Bianco, F., Devine, R. T., Hughes, C., \& Banerjee, R. (2014). Promoting theory of mind during middle childhood: A training program. Journal of Experimental Child Psychology, 126, 52-67. https://doi.org/10.1016/j.jecp.2014.03.002 
Legree, P. J., Psotka, J., Robbins, J., Roberts, R. D., Putka, D. J., \& Mullins, H. M. (2014). Profile similarity metrics as an alternate framework to score rating-based tests: MSCEIT reanalysis. Intelligence, 47, 159-174. http://doi.org/10.1016/j.intell.2014.09.005

Lim, K., Lee, S. A., Pinkham, A. E., Lam, M., \& Lee, J. (2019). Evaluation of social cognitive measures in an Asian schizophrenia sample. Schizophrenia Research: Cognition, 100169. https://doi.org/10.1016/j.scog.2019.100169

Lopes, P. N., Brackett, M. A., Nezlek, J. B., Schütz, A., Sellin, I., \& Salovey, P. (2004). Emotional intelligence and social interaction. Personality and Social Psychology Bulletin, 30(8), 1018-1034. https://doi.org/10.1177/0146167204264762

Lopes, P. N., Mestre, J. M., Guil, R., Kremenitzer, J. P., \& Salovey, P. (2012). The role of knowledge and skills for managing emotions in adaptation to school: Social behavior and misconduct in the classroom. American Educational Research Journal, 49(4), 710742. https://doi.org/10.3102/0002831212443077

Lopes, P. N., Salovey, P., Coté, S., \& Beers, M. (2005). Emotion regulation abilities and the quality of social interaction. Emotion, 5(1), 113-118. https://doi.org/10.1037/15283542.5.1.113

MacCann, C. (2010). Further examination of emotional intelligence as a standard intelligence: A latent variable analysis of fluid intelligence, crystallized intelligence, and emotional intelligence. Personality and Individual Differences, 49(5), 490-496. https://doi.org/ 10.1016/j.paid.2010.05.010

MacCann, C., Jiang, Y., Brown, L. E. R., Double, K. S., Bucich, M., \& Minbashian, A. (2020). Emotional intelligence predicts academic performance: A meta-analysis. Psychological Bulletin, 146(2), 150-186. https://doi.org/10.1037/bul0000219

MacCann, C., Joseph, D. L., Newman, D., \& Roberts, R. D. (2014). Emotional intelligence is a second-stratum factor of intelligence: Evidence from hierarchical and bifactor models. Emotion, 14(2), 358-374. https://doi.org/10.1037/a0034755

MacCann, C., \& Roberts, R. D. (2008). New paradigms for assessing emotional intelligence: Theory and data. Emotion, 8(4), 540-551. https://doi.org/10.1037/a0012746

Matthews, G., Zeidner, M., \& Roberts, R. D. (2012). Emotional intelligence: A promise unfulfilled? Japanese Psychological Research, 54(2), 105-127. https://doi.org/10.1111/ j.1468-5884.2011.00502.x

Mayer, J. D., Caruso, D., \& Salovey, P. (2016). The ability model of emotional intelligence: Principles and updates. Emotion Review, 8(4), 290-300. https://doi.org/10.1177/ 1754073916639667

Mayer, J. D., Roberts, R. D., \& Barsade, S. G. (2008). Human abilities: Emotional intelligence. Annual Review of Psychology, 59(1), 507-536. https://doi.org/10.1146/ annurev.psych.59.103006.093646

Mayer, J., \& Salovey, P. (1997). What is emotional intelligence? In P. Salovey \& D. Sluyter (Eds.), Emotional development and emotional intelligence: Educational applications (pp. 3-31). New York: Basic Books. 
Mayer, J. D., Salovey, P., Caruso, D. R., \& Sitarenios, G. (2001). Emotional intelligence as a standard intelligence. Emotion, 1(3), 232-242. https://doi.org/10.1037//1528-3542.1. 3.232

Mayer, J. D., Salovey, P., Caruso, D. R., \& Sitarenios, G. (2003). Measuring emotional intelligence with the MSCEIT V2.0. Emotion, 3(1), 97-105. https://doi.org/10.1037/ 1528-3542.3.1.97

McGrew, K. S. (2009). CHC theory and the human cognitive abilities project: Standing on the shoulders of the giants of psychometric intelligence research. Intelligence, 37(1), 110. http://doi.org/10.1016/j.intell.2008.08.004

Medina, R., Pérez-Alarcón, I., Reyes, M. L., Ceballos-Zúñiga, R., \& Mestre, J. M. (2012). Una Valoración Del Tesis (Test de Sensibilidad de Interacción Social) como criterio de la Inteligencia Emocional [A Thesis Assessment (Social Interaction Sensitivity Test) as the criterion of Emotional Intelligence]. In C. G. Ferreras, D. G. Manjón, R. Guil, \& J. M. Mestre (Eds.), Aportaciones recientes al estudio de la motivación y emociones (pp. 63-68). Sevilla, Spain: Kronos.

Mestre, J. M. (2003). Validación empírica de una escala para medir la inteligencia emocional, desde un modelo mixto, en una muestra de estudiantes de la Bahía de Cádiz [Empirical validation of a scale to measure emotional intelligence, from a mixed model, in a sample of students from the Bay of Cádiz]. (Unpublished doctoral dissertation). Universidad de Cádiz, Spain.

Mestre, J. M., \& Barchard, K. A. (2017). Four signs you have high emotional intelligence. The Conversation, 1-5. Retrieved from https://theconversation.com/four-signs-youhave-high-emotional-intelligence-71165

Mestre, J. M., \& Guil, R. (2006). Medidas de ejecución versus medidas de autoinformes de inteligencia emocional [Execution measures versus measures of emotional intelligence self-reports]. Ansiedad y Estrés, 12(2-3), 413-425.

Mestre, J. M., \& Guil, R. (2012). La regulación de las emociones: Una vía para la adaptación personal y social [The regulation of emotions: A way for personal and social adaptation]. Madrid: Pirámide.

Mestre, J. M., Guil, R., Lopes, P. N., Salovey, P., \& Gil-Olarte, P. (2006). Emotional intelligence and social and academic adaptation to school. Psicothema, 18, 112-117.

Mestre, J. M., Guil, R., Martinez-Cabañas, F., Larran, C., \& de la Torre, G. G. (2011). Validación de una prueba para evaluar la capacidad de percibir, expresar y valorar emociones en niños de la etapa infantil [Validation of a test to assess the ability to perceive, express and assess emotions in children of the childhood stage]. Revista Electrónica Interuniversitaria de Formación Del Profesorado, 14(3), 37-52.

Mestre, J. M., Gutierrez, J. M., Guerrero, C., \& Guil, R. (2017). La gestión de las emociones en el dia a dia [The management of emotions in everyday life]. Madrid: Pirámide.

Mestre, J. M., MacCann, C., Guil, R., \& Roberts, R. D. (2016). Models of cognitive ability and emotion can better inform contemporary emotional intelligence frameworks. Emotion Review, 8(4), 322-330. https://doi.org/10.1177/1754073916650497 
Mestre, J. M., Turanzas, J., García-Gómez, M., Guerra, J., Cordon, J. R., de la Torre, G. G., \& Lopez-Ramos, V. M. (2019). Do trait emotional intelligence and dispositional mindfulness have a complementary effect on the children's and adolescents' emotional states ? Frontiers in Psychology, 10, 1-11. https://doi.org/10.3389/fpsyg.2019.02817

Mikolajczak, M. (2009). Moving beyond the ability-trait debate: A three level model of emotional intelligence. E-Journal of Applied Psychology, 5, 25-31. https://doi.org/ 10.7790/ejep.v512.175

Nathanson, L., Rivers, S. E., Flynn, L. M., \& Brackett, M. A. (2016). Creating emotionally intelligent schools with RULER. Emotion Review, 8(4), 305-310. https://doi.org/ $10.1177 / 1754073916650495$

Nafukho, F. M. (2010). Emotional intelligence and performance: Need for additional empirical evidence. Advances in Developing Human Resources, 11(6), 671-689. http://doi.org/10.1177/1523422309360838

Oatley, K., \& Johnson-Laird, P. N. (2014). Cognitive approaches to emotions. Trends in Cognitive Sciences, 18(3), 134-140. https://doi.org/10.1016/j.tics.2013.12.004

Opateye, J. A. (2014). The relationship between emotional intelligence, test anxiety, stress, academic success and attitudes of high school students towards electrochemistry. Ife Psychologia, 22(1), 239-249.

Parker, J. D. A., Summerfeldt, L. J., Hogan, M. J., \& Majeski, S. A. (2004). Emotional intelligence and academic success: Examining the transition from high school to university. Personality and Individual Differences, 36(1), 163-172. https://doi.org/10. 1016/S0191-8869(03)00076-X

Pell, M. D., Jaywant, A., Monetta, L., \& Kotz, S. A. (2011). Emotional speech processing: Disentangling the effects of prosody and semantic cues. Cognition and Emotion, 25(5), 834-853. https://doi.org/10.1080/02699931.2010.516915

Peña-Sarrionandia, A., Mikolajczak, M., \& Gross, J. J. (2015). Integrating emotion regulation and emotional intelligence traditions: A meta-analysis. Frontiers in Psychology, 6, 160. https://doi.org/10.3389/fpsyg.2015.00160

Petrides, K., Frederickson, N., \& Furnham, A. (2004). The role of trait emotional intelligence in academic performance and deviant behavior at school. Personality and Individual Differences, 36(2), 277-293. https://doi.org/10.1016/S0191-8869(03)00084-9

Petrides, K. V., Mikolajczak, M., Mavroveli, S., Sanchez-Ruiz, M. J., Furnham, A., \& PérezGonzález, J. C. (2016). Developments in trait emotional intelligence. Emotion Review, 8(4), 335-341. https://doi.org/10.1177/1754073916650493

Plucker, J. A., \& Esping, A. (Eds.). (2014). Human intelligence: Historical influences, current controversies, teaching resources. Retrieved from http://www.intelltheory.com

Ruiz-Aranda, D., Cabello, R., Palomera, R., Extremera, N., Salguero, J. M., \& FernándezBerrocal, P. (2013). Programa INTEMO. Guía para mejorar la inteligencia emocional de los adolescentes [INTEMO program. Guide to improve the emotional intelligence of adolescents]. Madrid: Pirámide.

Salovey, P. (1991). The psychology of jealousy and envy. New York: Guilford. 
Salovey, P., Hsee, C. K., \& Mayer, J. D. (1993). Emotional intelligence and the self-regulation of affect. In D. M. Wegner \& J. W. Pennebaker (Eds.), Emotion regulation in couples and families: Pathways to dysfunction and health (pp. 258-277). Upper Saddle River, NJ: Prentice Hall.

Salovey, P., \& Mayer, J. D. (1990). Emotional intelligence. Imagination, Cognition and Personality, 9(3), 185-211. https://doi.org/10.1016/S0962-1849(05)80058-7

Sánchez-Álvarez, N., Extremera, N., \& Fernández-Berrocal, P. (2015). Maintaining life satisfaction in adolescence: Affective mediators of the influence of perceived emotional intelligence on overall life satisfaction judgments in a two-year longitudinal study. Frontiers in Psychology, 6, 1892. https://doi.org/10.3389/fpsyg.2015.01892

Schneider, W. J., \& McGrew, K. S. (2012). The Cattell-Horn-Carroll model of intelligence. In D. P. Flanagan \& P. L. Harrison (Eds.), Contemporary intellectual assessment: Theories, tests, and issues (pp. 99-144). New York City, NY: Guilford Press.

Schneider, W. J., \& Newman, D. A. (2015). Intelligence is multidimensional: Theoretical review and implications of specific cognitive abilities. Human Resource Management Review, 25(1), 12-27. http://doi.org/ 10.1016/j.hrmr.2014.09.004

Sharma, S., Deller, J., Biswal, R., \& Mandal, M. K. (2009). Emotional intelligence: Factorial structure and construct validity across cultures. International Journal of Cross Cultural Management, 9(2), 217-236. https://doi.org/10.1177/1470595809335725

Swart, M., Kortekaas, R., \& Aleman, A. (2009). Dealing with feelings: Characterization of trait alexithymia on emotion regulation strategies and cognitive-emotional processing. PLoS ONE, 4(6), 7. http://doi.org/10.1371/journal.pone.0005751

Toivonen, R., Kivelä, M., Saramäki, J., Viinikainen, M., Vanhatalo, M., \& Sams, M. (2012). Networks of emotion concepts. PLoS ONE, 7(1), e28883. https://doi.org/10.1371/ Citation

Turanzas, J. A., Cordón, J. R., Choca, J. P., \& Mestre, J. M. (2020). Evaluating the APAC (Mindfulness for giftedness) program in a Spanish sample of gifted children: A pilot study. Mindfulness, 11, 86-98. https://doi.org/10.1007/s12671-018-0985-1

UNESCO. (2014). Education strategy (2014-2021). United Nations Educational, Scientific and Cultural Organization, 1-63. Retrieved from https://unesdoc.unesco.org/ark:/ 48223/pf0000231288

Van den Broeck, W., Hofmans, J., Cooremans, S., \& Staels, E. (2014). Factorial validity and measurement invariance across intelligence levels and gender of the Overexcitabilities Questionnaire-II (OEQ-II). Psychological Assessment, 26(1). https://doi.org/10.1037/ a0034475

Vogel-Walcutt, J., Schatschneider, C., \& Bowers, C. (2011). Social-emotional functioning of elementary-age deaf children: A profile analysis. American Annals of the Deaf, 156(1), 6-22. Retrieved from www.jstor.org/stable/26235122

Vrtička, P., Bondolfi, G., Sander, D., \& Vuilleumier, P. (2012). The neural substrates of social emotion perception and regulation are modulated by adult attachment style. Social Neuroscience, 7(5), 473-493. https://doi.org/10.1080/17470919.2011.647410 
Waters, S. F., \& Thompson, R. A. (2014). Children's perceptions of the effectiveness of strategies for regulating anger and sadness. International Journal of Behavioral Development, 38(2), 174-181. https://doi.org/10.1177/0165025413515410

Wells, A. (2002). GAD, meta-cognition, and mindfulness: An information processing analysis. Clinical Psychology: Science and Practice, 9(1), 95-100. https://doi.org/10. 1093/clipsy.9.1.95

Whitmore, J. (1980). Giftedness, conflict and underachievement. Boston, MA: Allyn \& Bacon.

Windingstad, S., McCallum, R. S., Mee Bell, S., \& Dunn, P. (2011). Measures of emotional intelligence and social acceptability in children: A concurrent validity study. Canadian Journal of School Psychology, 26(2), 107-126. https://doi.org/10.1177/ 0829573511406510

Wranik, T., Barrett, L. F., \& Salovey, P. (2007). Intelligent emotion regulation: Is knowledge power? In J. J. Gross (Ed.), Handbook of emotion regulation (pp. 393-407). New York, NY: Guilford Press.

Yerkes, R. M., \& Dodson, J. D. (1908). The relation of strength of stimulus to rapidity of habit-formation. Journal of Comparative Neurology and Psychology, 18(5), 459482. https://doi.org/10.1002/cne.920180503

Zeidner, M. (2017). Tentative guidelines for the development of an ability-based emotional intelligence intervention program for gifted students. High Ability Studies, 28(1), 29-41. https://doi.org/10.1080/13598139.2017.1292895

Zenner, C., Herrnleben-Kurz, S., \& Walach, H. (2014). Mindfulness-based interventions in schools: A systematic review and meta-analysis. Frontiers in Psychology, 5, 1-20. https://doi.org/10.3389/fpsyg.2014.00603

Zimmermann, P., \& Iwanski, A. (2014). Emotion regulation from early adolescence to emerging adulthood and middle adulthood: Age differences, gender differences, and emotion-specific developmental variations. International Journal of Behavioral Development, 38(2), 182-194. https://doi.org/10.1177/0165025413515405/

Received: January 10, 2020 